\title{
Senescent cells: a therapeutic target for cardiovascular disease
}

\author{
Bennett G. Childs, ${ }^{1} \mathrm{Hu} \mathrm{Li},{ }^{2}$ and Jan M. van Deursen ${ }^{1,3}$ \\ 'Department of Biochemistry and Molecular Biology, ${ }^{2}$ Department of Molecular Pharmacology and Experimental Therapeutics, and ${ }^{3}$ Department of Pediatric and Adolescent Medicine, Mayo Clinic, \\ Rochester, Minnesota, USA
}

\begin{abstract}
Cellular senescence, a major tumor-suppressive cell fate, has emerged from humble beginnings as an in vitro phenomenon into recognition as a fundamental mechanism of aging. In the process, senescent cells have attracted attention as a therapeutic target for age-related diseases, including cardiovascular disease (CVD), the leading cause of morbidity and mortality in the elderly. Given the aging global population and the inadequacy of current medical management, attenuating the health care burden of CVD would be transformative to clinical practice. Here, we review the evidence that cellular senescence drives CVD in a bimodal fashion by both priming the aged cardiovascular system for disease and driving established disease forward. Hence, the growing field of senotherapy (neutralizing senescent cells for therapeutic benefit) is poised to contribute to both prevention and treatment of CVD.
\end{abstract}

\section{Introduction}

During aging, the human mortality rate rises exponentially as a result of a loss of normal organ functions, including tissue maintenance and repair capacity. Stressors that young tissue may tolerate because of excess functional reserve become insurmountable in the elderly, leading to age-related diseases (1). Age-related cardiovascular disease (CVD) is of particular clinical concern as the global population ages, with 1 billion individuals projected to be over 65 years old by 2030 . Indeed, $38 \%$ of people ages 40 to 60 and $83 \%$ of those over 85 have CVD (2). The primary diseases included under the umbrella of CVD are chronic heart failure (HF), hyper-tension, and coronary artery disease (CAD; atherosclerosis). Although hypertension and atherosclerosis can be pharmacologically managed, therapyresistant subpopulations exist for both these diseases $(3,4)$, and the long-term prognosis for HF remains poor (5). Given the growing patient population and the inadequacy of current medical management, there is strong incentive to identify new therapeutic targets to treat CVD or, more optimally, prevent it.

One mechanism behind age-related CVD maybe cellular senescence, a stress-response process by which damaged cells exit the cell cycle permanently and produce a proinflammatory senescenceassociated secretory phenotype (SASP) (1). The cellular senescence program serves an important tumor-suppressive function by growth-arresting preneoplastic cells. Normally, SASP factors target senescent cells (SNCs) for removal by the immune system, clearing adjacent, nonsenescent preneoplastic cells in the process and therefore providing tumor-suppressive benefits that are supe-

Conflict of interest: JMVD is a cofounder of Unity Biotechnology, a company developing senolytic medicines, including small molecules that selectively eliminate senescent cells. JMVD, HL, and BGC are co-inventors on patent applications licensed to or filed by Unity Biotechnology (15/455,630 and 62/057,825).

Reference information: J Clin Invest. 2018;128(4):1217-1228.

https://doi.org/10.1172/JCI95146 rior to apoptosis (6). However, long-term persistence of SNCs and their secretome drives cancer, atherosclerosis (7), and other major age-related diseases, in addition to aging itself (8-10). The solidifying link between SNCs, cardiovascular aging, and CVD depends on four lines of evidence. First, stressors that drive senescence, such as telomere shortening and oxidative stress, rise with aging and CVD in cardiovascular tissue (11-13). Second, SNC biomarkers are present at the same sites $(14,15)$. Third, prevention of the SNC fate by genetic elimination of senescence effectors can blunt agerelated loss of tissue function (16). Finally, and most compellingly, SNC-killing approaches block the effects of aging on cardiovascular performance (10), attenuate CVD (7), and may ultimately serve as therapies (17).

Based on these lines of evidence, here we propose a bimodal model for cellular senescence in CVD. Initially, primary SNCs accumulate in cardiovascular tissue with age, decreasing organ functional reserve and predisposing to age-related CVD. Then, as CVD develops, heightened cellular stress within the diseased tissue microenvironment produces a second wave of diseaseassociated SNCs (secondary SNCs). Secondary SNCs go on to exacerbate preexisting CVD. Because SNCs predispose to CVD as well as participate in pathophysiology, we posit that SNCs could be targeted both preventatively and therapeutically in CVD.

\section{Senescence-driven aging is a tradeoff for tumor suppression}

Hayflick and Moorhead showed in 1961 that human fibroblasts in vitro can divide a limited number of times before entering a permanent, stable growth arrest (18). This finite proliferative potential, now called replicative senescence, was swiftly proposed as a cell-autonomous mechanism for declining tissue repair capacity in aging (19). The primary molecular event responsible for this "senescence timer" in human cells is now known to be telomere attrition (Figure 1 and ref. 20). Owing to the nature of RNAtemplated DNA replication, approximately 50 to 100 base pairs 

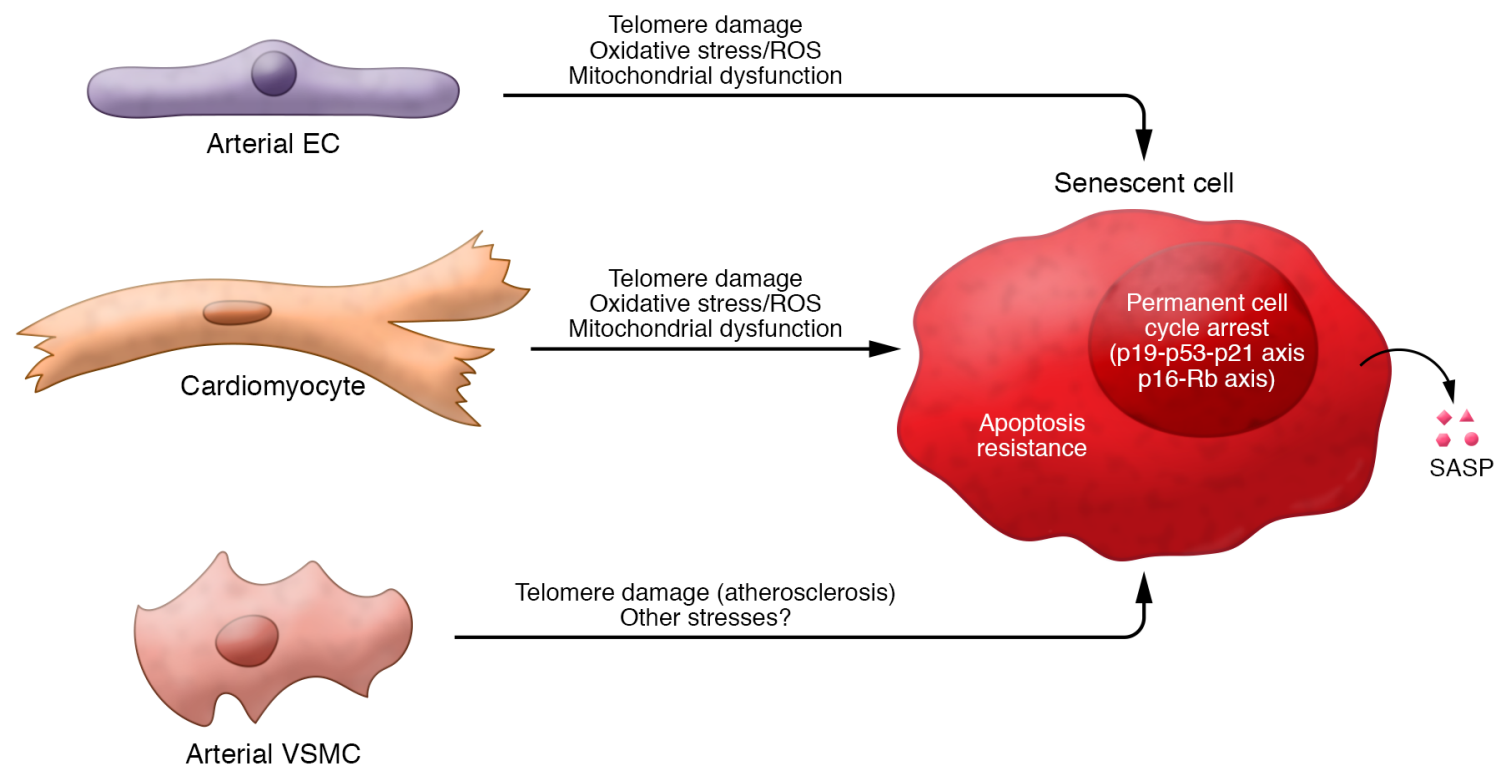

Figure 1. Key properties of senescent cells. In response to various types of stressors (generally irreparable macromolecular damage), replication-competent cardiovascular cells undergo senescence. The 3 major hallmarks of SNCs are a permanent cell cycle arrest, mediated by signaling through the p19Arf-p53p21 ${ }^{\mathrm{cip} / \mathrm{Waf}}$ and $\mathrm{p} 16^{\mathrm{Ink} 4 \mathrm{a}}-\mathrm{Rb}$ axes; apoptosis resistance, achieved by upregulation of prosurvival factors; and acquisition of the senescence-associated secretory phenotype (SASP), a bioactive secretome containing cytokines, growth factors, proteases, and other signaling molecules.

are lost from the ends of chromosomes with each cell division (21). Telomeres, comprising DNA hexanucleotide repeats complexed with protein, are protective caps terminating each chromosome that prevent this attrition from reaching coding sequences (22). More importantly, telomeres prevent DNA damage response (DDR) machinery from recognizing chromosome free ends as double-strand breaks (DSBs) and attempting erroneous repair, which could result in illegitimate recombination or chromosome fusion events. Fused chromosomes may break during mitosis, with repeated fusion/breakage cycles resulting in chromosomal instability, aneuploidy, and neoplastic transformation (23). Therefore, when telomeres become critically short, the DDR is activated and induces senescence to safeguard against replication with an unstable karyotype.

Elucidation of the molecular mechanisms behind replicative senescence has produced a framework for understanding senescence induction and maintenance. First, some form of molecular damage occurs and is recognized by a damage sensor, such as the apical ATM/R kinases in the case of DSBs (Figure 1). In addition to telomere erosion, other stressors that induce DSBs, such as oncogenic Ras expression $(24,25)$ and ionizing radiation (26), can also activate ATM/R to trigger senescence. Second, the cell engages effectors of a reversible cell-cycle arrest to halt proliferation and attempt repair. For example, Ras stabilizes p53 to upregulate the cyclin-dependent kinase 2 (CDK2) inhibitor $\mathrm{p} 21^{\mathrm{Cip} / \mathrm{Waf}}$, thereby blocking Rb phosphorylation and preventing S-phase entry. With Ras overexpression, p53 stabilization involves both p53 phosphorylation by ATM/R and, in mice, upregulation of p19 $9^{\text {Arf }}$, which blocks the ubiquitin ligase MDM2 from degrading p53. Third, should repair prove impossible, the cell enters senescence and permanently exits the cell cycle. Permanent cell-cycle withdrawal requires expression of additional CDK inhibitors (CDKis), most notably the CDK4/6 inhibitor $\mathrm{p} 16^{\text {Ink4a }}$ (27). Finally, the senescence state is reinforced through heterochromatinization of cell-cycle genes $(28,29)$ and the establishment of the SASP, which includes factors such as IL-6 that help maintain the cell-cycle arrest (30-33).

SNCs in vitro are known to produce numerous inflammatory cytokines, chemoattractant factors, proteases, and signaling molecules as part of the SASP (Figure 1 and refs. 30, 31). The SASP is a $16^{\text {Inka }}$-independent SNC property that can be either DDRdependent or -independent, but appears to rely on proinflammatory signaling through NF-kB, mTOR, and p38/MAPK (34-36). The SASP in vivo has diverse functions and, depending on biological context, can be beneficial or detrimental. For example, transient SNCs arising during wounding secrete PDGF-AA to hasten wound closure and are rapidly cleared (37). In contrast, ageassociated SNCs linger, driving tissue inflammation, dysfunction, and carcinogenesis presumably via the SASP $(8-10,38)$.

\section{Cellular senescence drives cardiovascular aging}

Major age-related changes in the cardiovascular system. Normal aging produces multiple alterations in the cardiovascular system that predispose to CVD. Crucially, arterial and cardiac health are tightly interrelated; it is therefore likely that interventions that enhance cardiac or arterial healthspan individually would have widespread benefits for CVD risk.

Aging results in arterial dysfunction at a structural and molecular level. In the arterial wall (media), elastic fiber degradation and enhanced collagen synthesis by vascular smooth muscle cells (VSMCs) result in arterial stiffening $(39,40)$. Increased arterial stiffness results in higher systolic and lower diastolic pressure (41), producing widened pulse pressure hypertension (42) that, together with aortic root dilation (43), increases cardiac afterload (44). When combined with hypertension, reduced elastic fiber content can predispose to aneurysms (45-47). Endothelial dysfunction 
with resultant decreased endothelial nitric oxide synthase (eNOS) activity contributes to these changes. Low NO tone promotes VSMC proliferation and collagen production $(48,49)$ and can also lead to vasoconstriction, predisposing to angina pectoris and ischemic heart injury $(50,51)$. Dysfunctional endothelial cells also secrete monocyte chemoattractant protein-1 (MCP-1) and present the leukocyte receptors VCAM1 and ICAM1 on their surfaces, thereby recruiting circulating monocytes and initiating atherogenesis (52). Upregulated NADPH oxidase (NOX) activity in dysfunctional endothelial cells can also shift eNOS toward production of superoxide anion, a reactive oxygen species (ROS), rather than NO, leading to inflammation and further dysfunction in a vicious cycle (53-55).

The normal aging heart employs several mechanisms to maintain resting systolic function and ejection fraction despite increased afterload (56). Structurally, the left ventricle (LV) thickens to normalize tension across the LV wall but does not increase in mass (48), instead shortening across the long axis. The cardiac cycle changes, shifting from early to late diastolic filling and prolonging isovolemic relaxation time (57). Atria-dependent diastolic filling is enhanced by left atria enlargement and increased contractility $(58,59)$. Systole is extended as a result of prolonged cardiomyocyte contraction, with a decrease in maximum heart rate driven by impaired SERCA2-dependent $\mathrm{Ca}^{2+}$ reuptake $(60-$ $62)$, attenuated responsiveness to $\beta$-adrenergic signaling, and increased $\omega 6 / \omega 3$ polyunsaturated fatty acid ratio in cardiomyocyte membranes (41).

Although the aforementioned cardiac changes are adaptive and preserve systolic function, this remodeling predisposes to stress-induced pathology. Left atrial dilation can cause atrial fibrillation and result in thrombosis (63). Reduced $\mathrm{Ca}^{2+}$ handling ability predisposes to cardiomyocyte death and further cellular hypertrophy. On this background of an aged heart with limited functional reserve, damage following myocardial infarction (MI) can produce HF (64). Crucially, despite adaptive cardiac changes, cardiovascular dynamics are still abnormal. For example, late systolic peak pressure, increased pulse wave velocity, and widened pulse pressure hypertension disrupt laminar flow that would normally trigger protective eNOS expression, resulting in endothelial dysfunction, atherogenesis, and CAD (65).

Prosenescence stressors increase in aging heart and vasculature. Despite being a largely nondividing cell type, cardiomyocytes from aged rats $(66)$ and mice $(67,68)$ show telomere shortening, as does healthy human heart tissue (69). Telomeric DNA is particularly susceptible to DSB-inducing oxidative stress (70) and accumulates DNA-damage foci with age (71), potentially explaining telomere dysfunction in noncycling cardiomyocytes. However, cell-cycle reentry of a small fraction of cardiomyocytes has been reported (72). Aged cardiomyocytes also show increased oxidative damage of mitochondrial lipids (73), mitochondrial dysfunction $(74,75)$, and ROS. Supporting a causal role for ROS in cardiac aging, old mice expressing mitochondrial-targeted catalase, which degrades $\mathrm{H}_{2} \mathrm{O}_{2}$ into water and $\mathrm{O}_{2}$, show longer lifespan, decreased LV hypertrophy, and reduced diastolic dysfunction $(76,77)$. Additional studies report significant age-related telomere shortening and reduced telomerase activity in human cardiac stem cells, a cKit-positive, CD45-negative cell type that replaces cardiomyocytes throughout life $(78,79)$.
Prosenescence stressors also rise in aged blood vessels. Telomere shortening occurs with normal aging in human large arteries $(12,13)$ and drives p53-dependent expression of the CDKi p21 (80) in endothelial cells (11). Intriguingly, circulating bone marrowderived early endothelial progenitor cells (EPCs) exhibit agedependent telomere shortening (81) and less telomerase activity (82). Aged human $(83)$ and murine $(84,85)$ arterial endothelial cells as well as EPCs $(86,87)$ also show heightened levels of ROS partially due to activation of NADPH oxidase, which uncouples eNOS $(83,88,89)$. Further study is needed to clarify whether these age-related changes to early EPC properties directly or indirectly affect endothelial homeostasis in vivo. Although human VSMCs undergo telomere shortening during atherosclerosis (15), this has not been demonstrated with normal aging. Collectively, these results suggest that prosenescence stressors, particularly telomere attrition and oxidative stress, are present throughout the aging cardiovascular system in the absence of frank age-related disease.

SNCs accumulate in the aging cardiovascular system. Reliably detecting SNCs in vivo is a major ongoing challenge to investigating their biological significance to the aging process. Currently, detection depends on a combination of SNC biomarkers, as any marker in isolation is prone to false positives. These include high expression of the CDKis $\mathrm{p} 16^{\text {Ink4a }}$ and $\mathrm{p} 21^{\mathrm{Cip} / \mathrm{Waf}}$; lysosomal hydrolase activity detectable at $\mathrm{pH}$ 6.0, known as senescenceassociated $\beta$-galactosidase (SA $\beta$-gal) (90); and expression of SASP-associated inflammatory, proteolytic, and signaling factors. Based on these markers, SNCs have been shown to accumulate in numerous tissues with age in humans, nonhuman primates (91), and rodents (10), including heart and arteries.

Aged murine hearts show increased expression of $\mathrm{p} 16^{\text {Ink4a }}$ (10), the p53-stabilizing protein p19 ${ }^{\text {Arf }}(10,91)$, and inflammatory SASP factors (10). Cardiac stem cells have also been shown to upregulate $\mathrm{p} 16^{\text {Ink4a }}$ and $\mathrm{p} 21^{\mathrm{Cip} / \mathrm{Waf}}$, potentially restricting their ability to produce new cardiomyocytes during aging and $\mathrm{HF}$ (78, 79). Surprisingly, a large fraction of postmitotic cardiomyocytes (about $85 \%$ ) in old hearts (72-104 years) were shown to be $16^{\text {Ink4a }}$ positive, versus approximately $30 \%$ in younger controls (19-49 years) (79). This high baseline may indicate that $\mathrm{p} 16^{\text {Ink } 4 \text { a }}$ expression is a normal differentiation step in cardiomyocyte commitment, as has been reported for macrophages (92), or that senescence may be a relatively early event. Consistent with this interpretation, young murine hearts contain a mixed pool of $\mathrm{p} 16^{\text {Ink4a }}$-positive, large cardiomyocytes with short telomeres and $\mathrm{p} 16^{\text {Ink4a }}$-negative, small cardiomyocytes (potentially replication-competent) with long telomeres (93). Low-frequency SA $\beta$-gal-positive cardiomyocytes have also been reported in aged mice (94) and rats (95).

These observations suggest that senescence in progenitor cell compartments could restrict cardiomyocyte replacement. However, the baseline ability of the adult human heart to renew cardiomyocytes, and how this changes with age, are controversial. Most studies report yearly replacement rates around 1\% for young adult mice $(96)$ and humans $(97,98)$. New cardiomyocytes reportedly arise from cardiac stem cells residing in the heart (99) and bone marrow-derived progenitors (100), as well as, strikingly, mature cardiomyocytes $(101,102)$. Therefore, unequivocally determining how senescence rates in these compartments change as a function of age is paramount. 
Visceral and serous pericardial epithelial cells, which belong to the trilayered, fibrous sac sheathing the heart, also show an age-related increase in SA $\beta$-gal activity and express p16 ${ }^{\text {Ink4a }}(10)$. Whereas the consequence of senescence in cardiac stem cells and cardiomyocytes is unknown, removal of $\mathrm{p} 16^{\text {Ink4a }}$-positive pericardial cells during normal aging in mice blunted cardiomyocyte hypertrophy, normalized cardiac stress tolerance, and reduced expression of inflammatory factors in the heart (10). This result supports the existence of prohomeostatic signaling from the pericardium to the ventricle that is disrupted by SNC accumulation, although the effect of SNCs at other sites cannot be ruled out.

Senescence also occurs with aging in both major arterial cell types, endothelium $(103,104)$ and VSMCs $(105-107)$. Endothelial NO produced by eNOS normally maintains VSMCs in a nondividing, contractile state and suppresses thrombogenic and inflammatory signaling in endothelium. This system's activity declines with age, partially because of heightened angiotensin II production (108). Intriguingly, NO production is reportedly decreased in senescent endothelial cells $(109,110)$. Reciprocally, NO activates telomerase (111) to prevent endothelial cell senescence, thereby decreasing presentation of the proatherogenic, leukocyte-binding receptors VCAM1 and ICAM1 (112). Similarly, NO production may inhibit VSMC senescence. Aged arterial VSMCs show elevated expression of $\mathrm{p} 16^{\text {Ink4a }}$ and SA $\beta$-gal activity (105-107), potentially due to aberrant cell-cycle reentry that results in polyploidization, greater levels of the NADPH oxidase NOX4, and ROS production. Additionally, aging raises circulating levels of angiotensin II, which activates the Ras signaling cascade, a well-known driver of oncogene-induced senescence (113), to produce VSMC senescence $(114,115)$ and enhance NADPH oxidase expression and ROS production (108). The SASP factors MMP2 and IL- 6 are also increased in aged VSMCs (116) as well as proatherogenic VCAM1, although whether these gene expression changes are restricted to senescent VSMCs is unknown.

Neutralizing SNCs prevents age-related cardiovascular impairment. Approaches now exist to block the senescence program or kill SNCs to study their contribution to the aging process. Early evidence that SNCs promote aging came from a mouse model of accelerated aging (progeria) caused by insufficiency of the mitotic checkpoint protein BubR1. BubR1-insufficient mice show several aging phenotypes, including loss of muscle mass (sarcopenia), adipose atrophy, and cataract formation. Dysfunctional skeletal muscle, fat, and eyes in BubR1-insufficient mice prematurely accumulate high levels of SNCs. When SNC formation was blunted by genetic deletion of the senescence effector $\mathrm{p} 16^{\text {Ink4a }}$, development of these degenerative phenotypes was blocked (16). However, this strategy could not distinguish between cell-autonomous deleterious effects of senescence, such as inhibited cycling of tissue-repairing progenitor cells, and paracrine effects of SNCs, such as the SASP.

To discriminate between these possibilities, an SNC suicide transgenic mouse (INK-ATTAC mouse), which permits INKlinked apoptosis through targeted activation of caspase, was developed (38). Briefly, this transgenic uses a $2.5-\mathrm{kbp}$ minimal fragment of the $16^{\text {Ink4a }}$ promoter to drive expression of a GFP reporter and an $\mathrm{FKBP} /$ caspase- 8 fusion protein in $\mathrm{p} 16^{\text {Ink4a }}$-positive SNCs. When mice are treated with an FKBP cross-linking ligand, AP20187, caspase- 8 dimerizes and activates to trigger apopto- sis of p16 ${ }^{\text {Ink4a }}$-positive cells. Lifelong removal of p16 ${ }^{\text {Ink4a }}$-positive SNCs in BubR1-progeroid mice using INK-ATTAC profoundly attenuated sarcopenia, fat loss, and cataract formation (38). However, progeroid mice incompletely recapitulate the complex tissue changes associated with normal aging. Furthermore, BubR1progeroid mice show several cardiovascular phenotypes, including arrhythmia, aortic VSMC loss, and intolerance to isoproterenol stress that are not corrected by SNC killing via INK-ATTAC in this model of aging (117).

To test the contribution of SNCs to normal aging, including cardiovascular aging, transgene-mediated SNC killing was repeated in naturally aged mice. Wild-type INK-ATTAC mice were aged to 12 months (approximately middle-aged) before receiving twice-weekly administration of AP20187 or vehicle to remove SNCs (10). SNC clearance resulted in a sex- and strainindependent increase in median lifespan with corresponding reduction of SNC markers in several vital organs, including heart and kidney. At 18 months, SA $\beta$-gal-positive SNCs were identified by transmission electron microscopy in the visceral and serous pericardium of the heart as well as the renal proximal tubule epithelium. AP20187 treatment removed these SNCs, thereby blunting age-related cardiomyocyte hypertrophy and glomerulosclerosis. In the heart, SNC clearance increased tolerance to a lethal dose of isoproterenol, a $\beta$-adrenergic agonist, and reduced development of diastolic dysfunction when mice were challenged with sublethal, chronic isoproterenol (10). In the kidney, SNC removal blunted activity of the renin-angiotensin-aldosterone system (RAAS), reducing glomerulosclerosis and blood urea nitrogen, a surrogate marker of kidney function. Although these results are consistent with local action of pericardial and renal SNCs, INK-ATTAC also clears SNCs at other distal sites, such as adipose and skeletal muscle. Tissue-specific SNC clearance models will be necessary to disentangle global versus local effects of SNCs on cardiovascular function.

\section{Senescent cells drive age-related cardiovascular diseases}

Although SNCs accumulate with normal aging in cardiovascular tissues, SNCs arise locally in comparably larger numbers as a result of cellular stressors experienced during age-related diseases. We term these "secondary SNCs," in contrast to primary SNCs that arise with basal aging. Primary and secondary SNCs may be different cell types or arise due to different stressors, thereby possessing distinct properties including unique SASPs. To illustrate the bimodal role of SNCs in age-related CVD, we will explore two major age-related disease processes: atherosclerosis and HF.

Atherosclerosis. During atherogenesis, an aberrant lipid profile drives oxi-LDL retention in the subendothelial space. This prompts circulating monocytes to invade, where they differentiate, take up oxi-LDL, and convert to foam cell macrophages (118). These foam cells secrete cytokines and chemokines such as IL-1 $\alpha$, TNF- $\alpha$, and MCP-1 to drive further immune cell recruitment and form an atherosclerotic plaque $(118,119)$. CAD and deaths from atherosclerosis complications (MI, ischemic heart disease, and thromboembolic stroke) rise dramatically with age but can also occur earlier given appropriate stressors such as diabetes, meta- 


\section{Young vesse}
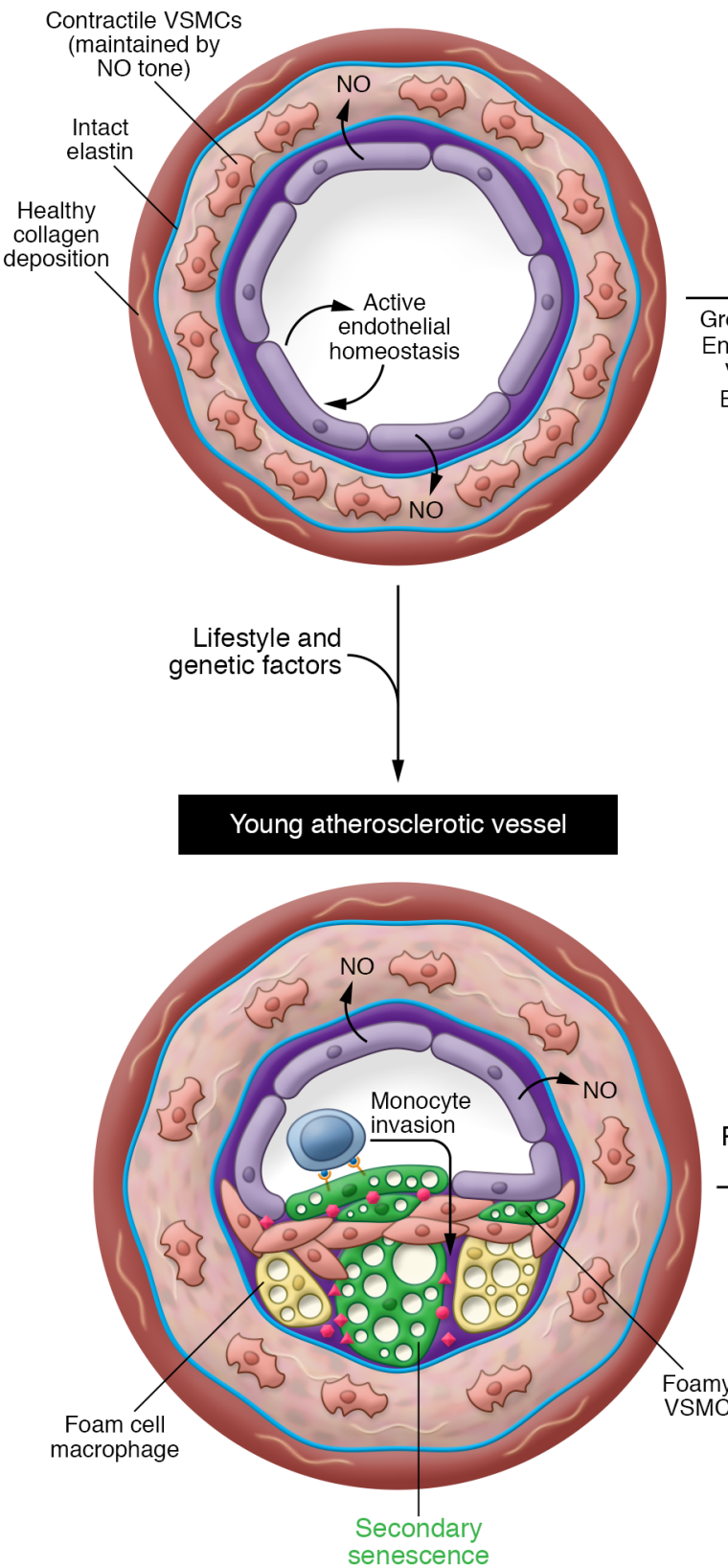

Aged vessel

Primary

senescence
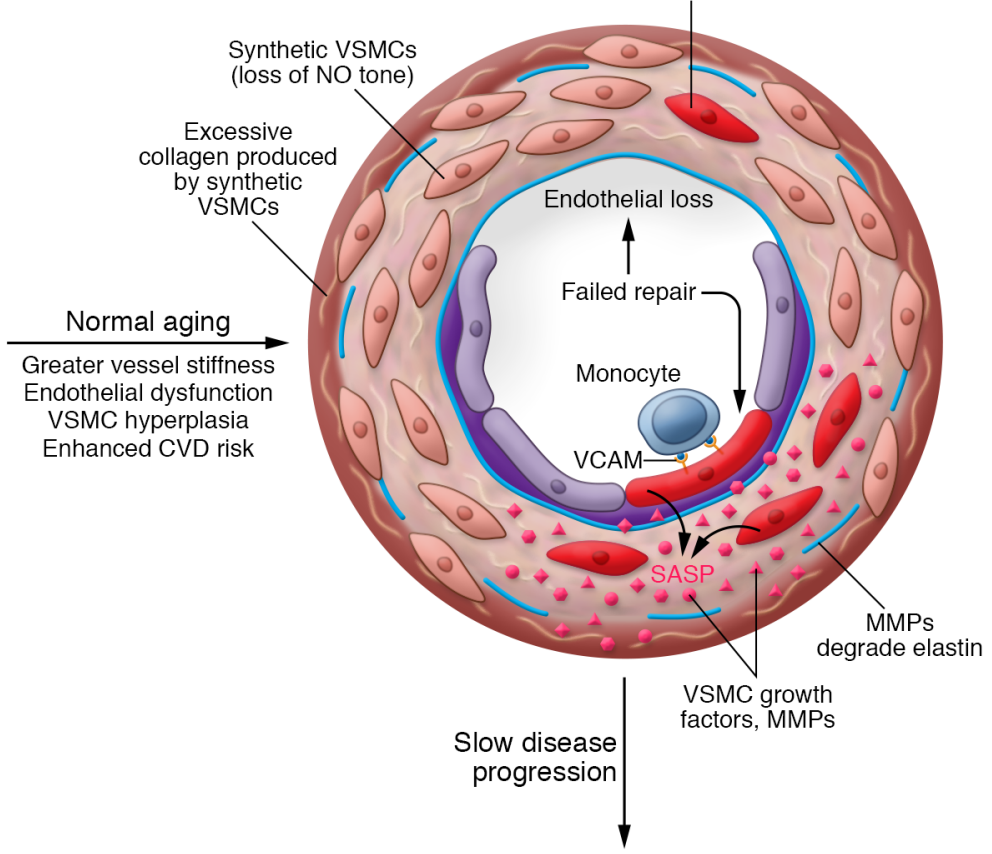

Advanced atherosclerotic vessel

Rapid disease progression

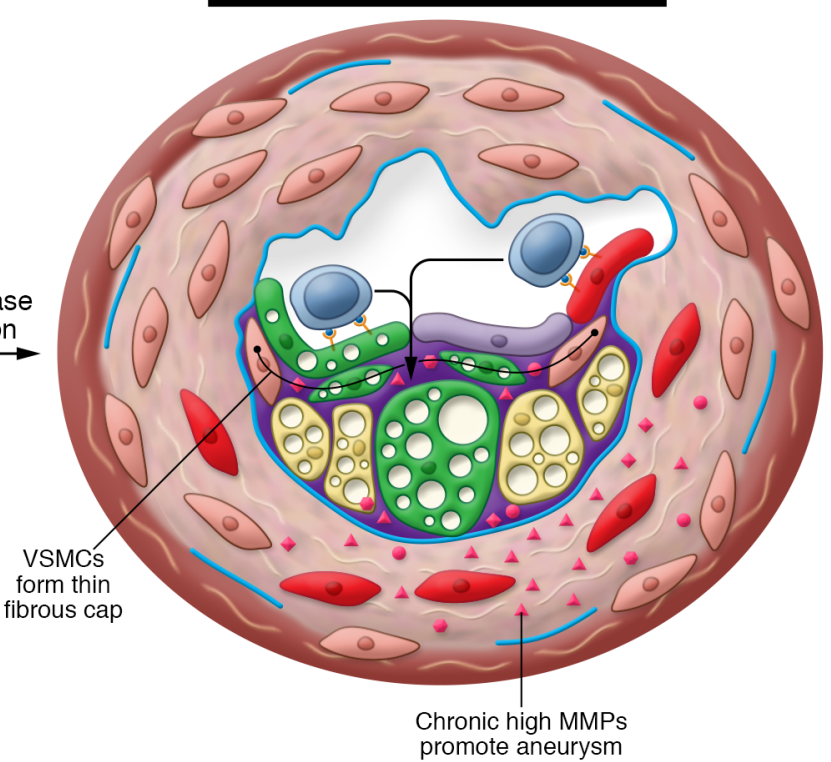

Figure 2. Cellular senescence is a cause and consequence of atherosclerosis. Both primary (age-derived) SNCs and secondary (atherosclerosis-derived) SNCs may promote atherosclerosis. In young arteries (top left), senescence burden is low. Vessel homeostasis is achieved by endothelium-derived NO acting on VSMCs, promoting vasodilation, quiescence, contractile phenotype, and endothelial health. During normal aging (top right), endothelial cells and VSMCs undergo primary senescence (red cells). Loss of NO tone may arise due to failure of endothelial cell homeostasis, leading to endothelial dysfunction and senescence. Excessive VSMC proliferation in aging vessels may also drive VSMC senescence, further exacerbating VSMC hyperplasia via SASP-mediated growth factor release. Whatever the causal chain, loss of NO tone converts VSMC to the synthetic phenotype, prompting VSMC hyperplasia, medial thickening, collagen overproduction, and synthesis of elastin-degrading metalloproteases (MMPs), collectively producing vessel stiffening, widened pulse pressure, hypertension, and increased cardiac afterload. Vessel stiffening interrupts normal shear stress signals that suppress VCAM expression, with proatherogenic effects. Absence of risk factors in late life may produce late-onset cardiovascular disease (CVD; bottom right). Alternatively, early-life CVD risk factors (e.g., diabetes, hypertension, metabolic syndrome, and dyslipidemia) promote aberrant oxi-LDL accumulation in the subendothelial space, initially producing secondary senescent foam cell macrophages. At later stages of disease, secondary senescent foamy endothelium and VSMCs also arise (green cells). This faster trajectory results from intense, proatherogenic stress and results in early CVD (bottom left). The relative contribution of primary and secondary SNCs to atheroprogression probably varies with life history and personal risk factors, but both types likely contribute to key features of clinical disease, including thinning of the fibrous cap as a result of VSMC growth arrest and SASP-derived collagenases and elastases; enhanced lesion growth due to expression of VCAM and ICAM; and lesion-associated aneurysm resulting from medial elastin degradation. 
bolic syndrome, and an abnormal circulating lipid profile (120). One interpretation of these facts is that the aging cardiovascular system becomes abnormally sensitive to proatherogenic stressors. Alternatively, the high rate of atherosclerosis in the elderly may represent the inevitable result of slow progression of subclinical disease over decades, and therefore atherosclerosis may not be a "true" age-related disease (i.e., one in which biological age rather than length of disease progression is a causal factor).

Although this question is largely unresolved, proatherogenic mechanisms are active in primary SNCs of normally aging arteries (Figure 2, top right). Dysfunctional and senescent endothelial cells present VCAM1 and ICAM1, which bind circulating monocytes to drive their invasion (112). Senescent endothelial cells in vitro also show apoptosis susceptibility and impaired tight junction formation, both of which could enhance oxi-LDL retention in the subendothelium $(121,122)$. EPC senescence may contribute in part to endothelial cell dysfunction through failed repair. IL- 6 and MCP-1 produced by aged VSMCs may contribute to the atherogenic milieu $(123,124)$.

Secondary SNCs also arise during atherogenesis, thereby driving lesion expansion and deleterious remodeling by producing an inflammatory, proteolytic environment (refs. 7, 13-15, 125, and Figure 2, bottom left). Early "fatty streak" lesions contain p16 $6^{\text {Ink4a }}$ positive, SA $\beta$-gal-positive foam cell macrophages and can be largely ablated in the $\mathrm{Ldlr}^{-}$model of atherosclerosis using transgenic or pharmacological approaches to kill SNCs (7). This preventative benefit of SNC killing extends to intermediate and advanced lesions, which contain senescent foamy endothelium and VSMCs in addition to senescent foam cell macrophages. Mechanistically, SNC removal reduced expression of the atherogenic cytokines IL- $1 \alpha$ and TNF- $\alpha$, as well as MCP-1 (7). Importantly, SNC removal blocked thinning of the fibrous cap, a VSMC- and extracellular matrix-rich structure that contains the plaque to prevent rupture, clotting cascade engagement, and thromboembolism (126). A cap-stabilizing effect of senolysis is consistent with direct production of elastase and collagenase by SNCs as part of the SASP. Indeed, a study using GFP expression in $\mathrm{Ldlr}^{-/}$INK-ATTAC mice to flow-sort lesional SNCs showed that these cells express higher levels of the elastase MMP12, the collagenase MMP13, IL-1 $\alpha$, and MCP-1 than their nonsenescent counterparts (7). Age-related atherosclerosis likely features contributions from primary and secondary SNCs, and occurs earlier or later in life depending on whether proatherogenic stressors or aging make the larger contribution, respectively (Figure 2, bottom right).

By contrast, the proliferative senescence arrest may initially restrict atherosclerotic lesion development. In murine models of high-fat diet-induced atherogenesis, deficiency of any of the senescence effector genes p21 (127), p27 ${ }^{\text {Kip }}$ (128), and p53 (129) resulted in greater lesion burden than controls. Similarly, human genomewide association studies have shown that polymorphisms in the senescence-modulating 9p21.3 locus increase the risk of MI and stroke $(130,131)$. This locus contains several senescence effectors, including the CDKN2a gene, which codes for $19^{\text {Arf }}$ and p16 ${ }^{\text {Ink4a }}$, and the $C D K N 2 b$ gene, encoding $\mathrm{p} 15^{\text {Ink } 4 \mathrm{~b}}$. 9p 21.3 also contains $C D K N 2 b$ AS1, encoding the long noncoding RNA ANRIL, whose expression directs inhibitory methylation of $C D K N 2 a / b(132,133)$. Presence of the CAD 9p21.3 risk locus increases ANRIL expression to inhibit senescence and promote proliferation in lesional VSMCs (134-136) and macrophages (134). This dichotomy may be analogous to the role of senescence in cancer, where senescence initially disarms preneoplastic cells but persistent SASP production promotes future carcinogenesis $(8,9,137)$.

Heart failure. Although aging itself does not cause HF, the aging heart is predisposed to develop HF for multiple reasons. Adaptations that the aging heart undergoes to preserve resting systolic function, such as LV thickening (138), cardiomyocyte hypertrophy (139), and decreased response to $\beta$-adrenergic stimulation (140), deplete the functional reserve that can be deployed to deal with disease or heightened demand (41). Additionally, repair processes such as cardiomyocyte replacement are impaired (141), and others, such as fibrosis, can become exaggerated and maladaptive. Finally, further injury from ischemic disease, such as CAD, increases with age. Given that an increasing proportion of elderly HF patients maintain normal systolic function (HF with preserved ejection fraction; $\mathrm{HFpEF}$ ), a difficult-to-treat subtype of the disease, the need for new preventative and therapeutic strategies is paramount (5).

Cellular senescence drives these three aspects of HF predisposition in the aging mouse heart (Figure 3, A and B). For example, old but not young mice show increased LV mass and diastolic dysfunction when challenged with repeated, low-dose isoproterenol, a $\beta$-adrenergic agonist (10). In contrast, old mice cleared of SNCs via INK-ATTAC do not show such dysfunction (10). SNC killing also attenuates other HF risk factors, including diet-induced atherogenesis (7) and age-related cardiomyocyte hypertrophy (10), potentially by normalizing homeostatic signaling from pericardium to myocardium (Figure $3 \mathrm{~A}$ ).

SNCs also accumulate during HF itself (Figure 3C). Aged human hearts with dilated cardiomyopathy show greater numbers of $16^{\text {Ink4a }}$-positive, cKit-positive progenitor cells and cardiomyocytes with short telomeres than age-matched controls (142). Although cell division was increased in both cell types during $\mathrm{HF}$ and cardiomyocytes become hypertrophic, this could not match the rate of cell death or compensate for reduced function, resulting in HF (142). Similarly, human cardiac stem cells (hCSCs) from failing hearts showed increased $\mathrm{p} 16^{\text {Ink4a }}$ and inflammatory factor expression (78). Supporting a causal role for senescence in HF, telomerase-deficient mice show enhanced cardiomyocyte death and hypertrophy leading to HF (143). Similarly, senescence-accelerated mice (SAM), a naturally progeroid mouse strain, develop HFpEF with LV hypertrophy, atrial dilation, and fibrosis when fed a high-fat/high-salt diet that drives endothelial cell senescence (144).

In addition to perhaps removing cardiomyocytes with proliferative potential from the cycling pool via cell-cycle arrest, senescence in HF may also drive signaling changes that predispose to cardiomyocyte death or dysfunction. For example, RAAS hyperactivity occurs in HF, driving aberrant ROS production and cardiomyocyte death (145-147). Age-related senescence in the kidney enhances expression of angiotensin-converting enzyme (ACE) and increases levels of the angiotensin II receptor, driving glomerulosclerosis (10). It is plausible that SNCs in the aged or failing heart also aberrantly elevate RAAS activity, but this is currently unknown. Given that ACE inhibitors are a mainstay of HF therapy (148) and RAAS hyperactivity is a key driver of age-associated 
A

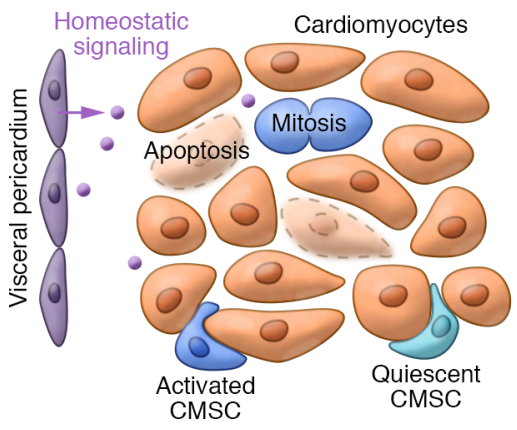

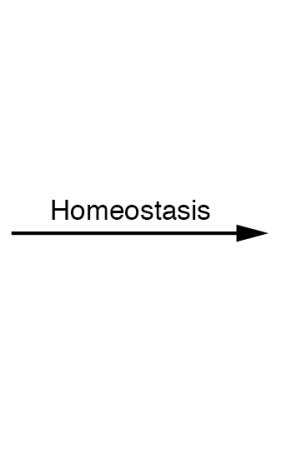

B

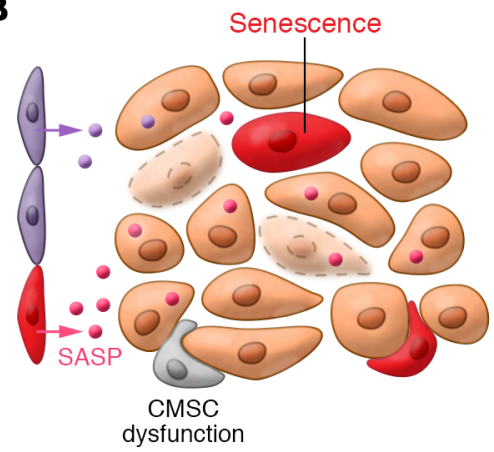

C

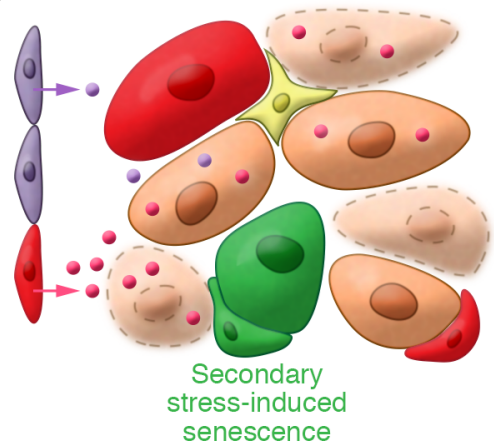

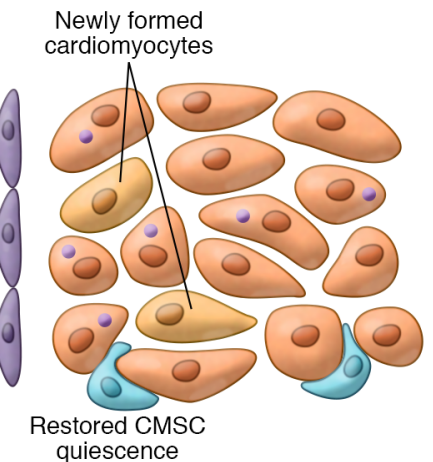

Response to stress

Restoration of normal architecture

High stress tolerance

High cardiac reserve
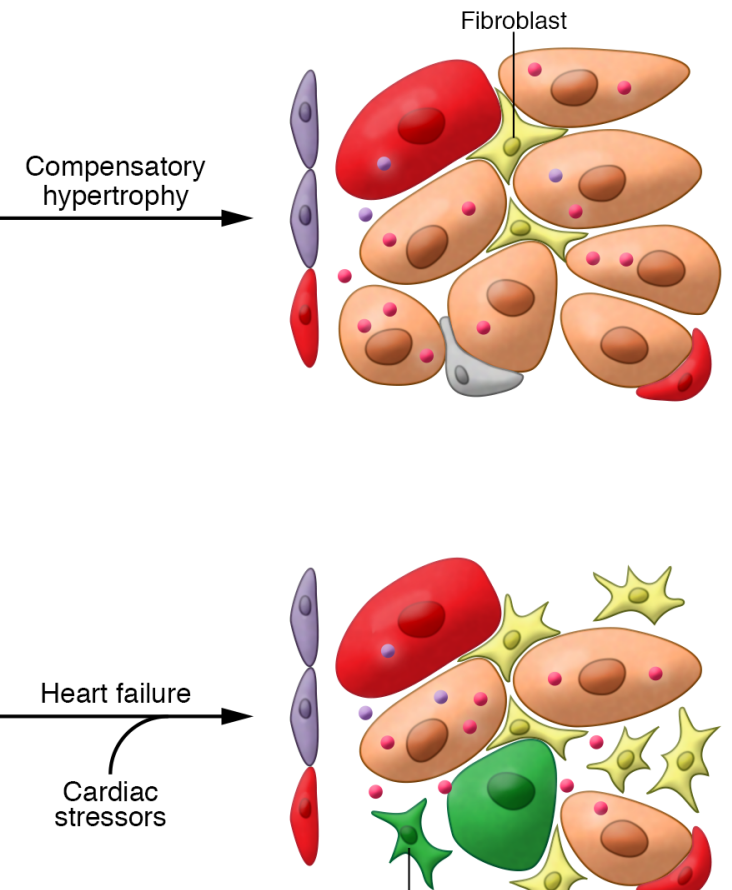

Response to stress

Cardiomyocyte hypertrophy

Reduced stress tolerance

Low cardiac reserve

Fibrosis

Susceptibility to heart failure
Response to stress

Uncompensated cardiomyocyte apoptosis Fibrosis leading to conduction defects Arrhythmia

Death

Figure 3. Senescent cells drive heart failure. (A) In young hearts, myocardium homeostasis, normal tissue function, and excess cardiac reserve are maintained through de novo formation of cardiomyocytes from resident cardiomyocyte stem cells (CMSCs) or division of incompletely differentiated, small cardiomyocytes. New cardiomyocyte formation matches a relatively low rate of cardiomyocyte apoptosis (purple cells). Appropriate CMSC function, including return to quiescence and suppression of cardiomyocyte death, may be maintained by homeostatic signals arising from the pericardium. (B) In disease-free, aging hearts, a declining ability to replace apoptotic cardiomyocytes due to progenitor dysfunction/senescence conspires with an increasing rate of cardiomyocyte death to produce compensatory hypertrophy. In the resting state and in the absence of further CVD, this adaptive change partially preserves heart function but predisposes to heart failure upon further stress. Interestingly, the INK-ATTAC SNC-killing transgenic strategy efficiently removes SA $\beta$-gal-positive pericardial SNCs from aged mice and prevents both cardiomyocyte hypertrophy and declining $\beta$-adrenergic stress tolerance. Based on this, we propose the existence of pericardium-derived prohomeostatic signaling that is disrupted during aging by pericardial SASP factors, although similar disruptive signaling may arise from senescent cardiomyocytes, CMSCs, or other cell types in the myocardium. (C) When challenged with cardiovascular stressors, such as ischemia in coronary artery disease, diabetes, or hypertension, the aged myocardium exceeds its functional reserve and decompensates. Apoptotic cardiomyocytes are not replaced, hypertrophy no longer preserves function, and excessive fibrosis leads to conduction defects, arrhythmia, and HF. To some extent, fibroblast senescence restricts fibrosis, but the long-term presence of these and other SNC types in the failing heart is suspected to be deleterious. It is currently unclear whether SNC removal can improve established heart failure or merely blunts development.

cardiovascular inflammation (149), investigating the link between senescence and the RAAS is a high priority.

HF patients often also show increased myocardial fibrosis, which interrupts normal propagation of electrical signals and drives arrhythmias (Figure 3C and ref. 150). Interestingly, the senescence cell-cycle arrest can halt expansion of fibrosis (151,
152) (Figure 3C). Mice lacking the senescence effector $\mathrm{p} 16^{\text {Ink4a }}$ or p53 showed greater fibrosis and greater diastolic dysfunction when challenged with pressure overload aortic banding than controls with an intact senescence program (153). Similarly, in postMI ventricle, arrhythmic atria, and pressure-overloaded ventricle, $\mathrm{p} 16^{\text {Ink4a }}$-positive and SA $\beta$-gal-positive cells are detected in 
fibrotic regions (153-155). In atrial fibrillation (AF) patients, higher rates of $\mathrm{AF}$ recurrence and fibrosis were found in individuals with lower SNC numbers (154). Although restriction of proliferation is a plausible mechanism for the antifibrotic effect, expression of matrix-degrading collagenases or other tissue remodeling factors as part of the SASP of senescent myofibroblasts may also restrict fibrosis (37). It is unclear whether eliminating senescent fibroblasts from the failing heart would have a beneficial or a deleterious effect.

\section{Senotherapy's potential for treating or preventing CVD}

SNCs are an attractive target for preventing and treating CVD for several key reasons. First, SNCs accumulate slowly throughout the lifespan, are nondividing, and, in relatively small numbers, "poison" the tissue microenvironment, leading to organ dysfunction and heightened susceptibility to age-related disease. These characteristics suggest that SNC-killing therapies (senolytics) could be administered at infrequent intervals. Importantly, unlike cytotoxic anticancer chemotherapy, selection of drug-resistant clones is unlikely to produce therapy resistance during senolysis.

Second, the beneficial functions of SNCs are temporally restricted, allowing senotherapy's timing to selectively neutralize deleterious SNCs. For example, the senescence cell-cycle arrest assists in organ patterning $(156,157)$ and placental syncytiotrophoblast formation (158) during embryogenesis, which would be irrelevant for treating age-related CVD. SNC secretion of PDGFAA (37) has also been reported to assist in wound closure. In most cases of trauma, this would simply require suspending senolytic therapy temporarily. However, in nonhealing chronic ulceration, a common malady in diabetic patients with peripheral artery disease (159), use of senolytics may be contraindicated (although whether SNCs exist in chronic wounds or have a similar function as in normal wound closure is unknown). Finally, by permitting cell-cycle arrest and then removing SNCs, senolysis may preserve select beneficial functions of SNCs, such as restriction of fibrosis in $\mathrm{HF}$ and tumor suppression. Accordingly, removing SNCs in old mice using the transgenic INK-ATTAC approach does not lead to greater fibrosis or cancer incidence (10).

Third, and finally, the first generation of SNC-killing molecules have been described (see Childs et al., ref. 17, for an extensive overview). Existing senolytics work by targeting prosurvival adaptations that are engaged in SNCs but not active in replicationcompetent or terminally differentiated cells. For example, SNCs generally resist apoptosis despite macromolecular damage, in part by upregulating the antiapoptotic proteins BCL-2, BCL-XL, and BCL-W (160-162). Inhibition of BCL-family members using navitoclax (ABT-263) licenses BAX and BAD assembly at the mitochondrial outer membrane, forming the mitochondrial transmembrane pore and releasing cytochrome $c$ to trigger the apoptotic caspase cascade (163). Navitoclax has proven able to remove SNCs during atherogenesis to blunt further lesion development (7) and kill hematopoietic SNCs to rejuvenate aged or irradiated marrow (164). The related BCL-W/BCL-XL inhibitor venetoclax also clears irradiation-induced lung SNCs and skin SNCs produced by p19 Arf overexpression (162). Other molecules that reportedly have senolytic properties include a peptide FOXO4 mimetic, which titrates endogenous FOXO4 away from p53, triggering cytoso- lic retention of p53 and SNC death (165); HDAC inhibitors (166); HSP9O inhibitors (167); piperlongumine (168); and dasatinib and quercetin (169). However, more work is needed to independently confirm the senolytic properties of these molecules and determine to what extent their healthspan benefits derive from SNC killing. For example, dasatinib and quercetin do not kill senescent IMR-90 (human fetal lung) fibroblasts (165) or reduce p16 ${ }^{\text {Ink4a }}$ expression in aged aortas (170), but nonetheless improve vasomotor function in aged mice (170).

The major challenges currently facing therapeutic exploitation of senolysis are senolytic selectivity and potency. Local administration of senolytic drugs may help resolve both of these concerns by achieving high local drug concentrations at the site of pathology. This has been demonstrated recently for the senolytic UBX101, which reduced senescent chondrocyte load and improved disease in a murine injury-induced arthritis model following intra-articular injection (171). Similar local administration of senolytics may be of use in treating CVD. For example, sirolimuseluting stents are frequently used during coronary artery stenting in CAD to preventVSMC proliferation, immune cell infiltration, and vessel restenosis (172). A senolytic-eluting stent could provide the antiatherogenic benefits of systemic navitoclax administration without as many concerns about off-target effects. Alternatively, a senolytic-eluting "patch" could be applied directly to the heart surface to remove SNCs following MI.

\section{Conclusion and outlook}

In the last two decades, SNCs have emerged as bona fide drivers of aging and age-related CVD. The evidence supporting this consists of detection of SNC biomarkers in diseased tissues; alteration of disease pathophysiology following genetic disruption of the senescence program; disruption of disease course via transgene-mediated SNC killing; and modification of pathology by administration of senolytics. Collectively, these advances suggest that SNCs are a viable target for senotherapy to treat and possibly prevent CVD.

Despite our growing understanding of in vivo SNC biology, major knowledge gaps continue to hamper the translational development of SNCs as a therapeutic target. Crucially, a consensus on universal SNC biomarkers is still lacking (reviewed by Sharpless et al., ref. 173). The current gold standard is to use a panel of markers, such as high $\mathrm{p} 16^{\text {Ink4a }}$, SASP expression, and SA $\beta$-gal activity, to detect SNCs. However, this approach risks false negatives arising from genuine SNCs that do not express canonical markers, and false positives due to biological use of these proteins outside of senescence. For example, some speculate that macrophages recruited to SNCs as part of immune surveillance make up a large portion of $16^{\text {Ink4a }}$-positivity and SA $\beta$-gal signal in aged tissue without being senescent per se (174-176).

Refining SNC biomarkers depends on building a comparative understanding of the in vivo biological properties of SNCs. In and of itself, this is a major knowledge gap. For example, how does the SASP change with SNC type, with prosenescence stress, and over time? Do all in vivo SNCs share the same susceptibility to a given senolytic, or do some SNCs favor different apoptosis-resistance mechanisms? Finding answers to these simple-to-frame questions is currently hindered by lack of tools to extract and purify in vivo 
SNCs across tissues before analysis by high-throughput transcriptomic or proteomic means. While the INK-ATTAC reporter mouse has been used in several studies to separate $\mathrm{p} 16^{\text {Ink4a }}$-positive and -negative cell fractions, it has not been successfully applied to produce an "atlas" of SNCs.

The next generation of SNC reporter mice will hopefully surmount the major technical challenges: low SNC number in vivo, age-related autofluorescence, and the need to rapidly acquire and process isolated cells to avoid artifactual changes to cell properties. This tool should also be compatible with means of identifying cell type, such as coimmunofluorescence staining or electron microscopy, and, if possible, be inducible such that SNCs can be tracked over time. Achieving the goal of a comparative "atlas" of SNCs across aged and diseased tissues will both clarify which SNC biomarkers are most universal and uncover new biology.

\section{Acknowledgments}

The authors would like to acknowledge the Glenn Foundation for Medical Research and grants R01CA096985 (NIH) and R01AG057493 (NIH).

Address correspondence to: Jan M. van Deursen, 200 1st St. SW, Rochester MN 55902, USA. Phone: 507.284.8417; Email: vandeursen.jan@mayo.edu.
1. Childs BG, Durik M, Baker DJ, van Deursen JM. Cellular senescence in aging and age-related disease: from mechanisms to therapy. Nat Med. 2015;21(12):1424-1435.

2. Roger VL, et al. Heart disease and stroke statistics - 2011 update: a report from the American Heart Association. Circulation. 2011;123(4):e18-e209.

3. Feingold KR, Grunfeld C. Approach to the patient with dyslipidemia. In: De Groot $G$, et al., eds. Endotext [Internet]. South Dartmouth, Massachusetts, USA; 2000. https://www.ncbi.nlm.nih.gov/ books/NBK278943/. Accessed January 29, 2018.

4. Acelajado MC, et al. Refractory hypertension: definition, prevalence, and patient characteristics. J Clin Hypertens (Greenwich). 2012;14(1):7-12.

5. Upadhya B, Taffet GE, Cheng CP, Kitzman DW. Heart failure with preserved ejection fraction in the elderly: scope of the problem. JMol Cell Cardiol. 2015;83:73-87.

6. Childs BG, Baker DJ, Kirkland JL, Campisi J, van Deursen JM. Senescence and apoptosis: dueling or complementary cell fates? EMBO Rep. 2014;15(11):1139-1153.

7. Childs BG, Baker DJ, Wijshake T, Conover CA, Campisi J, van Deursen JM. Senescent intimal foam cells are deleterious at all stages of atherosclerosis. Science. 2016;354(6311):472-477.

8. Ruhland MK, et al. Stromal senescence establishes an immunosuppressive microenvironment that drives tumorigenesis. Nat Commun. 2016;7:11762.

9. Lee JS, et al. Tumor stroma with senescenceassociated secretory phenotype in steatohepatitic hepatocellular carcinoma. PLoS One. 2017;12(3):e0171922.

10. Baker DJ, et al. Naturally occurring p16(Ink4a)-positive cells shorten healthy lifespan. Nature. 2016;530(7589):184-189.

11. Aviv H, et al. Age dependent aneuploidy and telomere length of the human vascular endothelium. Atherosclerosis. 2001;159(2):281-287.

12. Chang E, Harley CB. Telomere length and replicative aging in human vascular tissues. Proc Natl Acad Sci U S A. 1995;92(24):11190-11194.

13. Okuda K, Khan MY, Skurnick J, Kimura M, Aviv H, Aviv A. Telomere attrition of the human abdominal aorta: relationships with age and atherosclerosis. Atherosclerosis. 2000;152(2):391-398.

14. Minamino T, Miyauchi H, Yoshida T, Ishida Y, Yoshida H, Komuro I. Endothelial cell senescence in human atherosclerosis: role of telomere in endothelial dysfunction. Circulation. 2002;105(13):1541-1544.
15. Matthews C, et al. Vascular smooth muscle cells undergo telomere-based senescence in human atherosclerosis: effects of telomerase and oxidative stress. Circ Res. 2006;99(2):156-164.

16. Baker DJ, et al. Opposing roles for p16Ink4a and p19Arf in senescence and ageing caused by BubR1 insufficiency. Nat Cell Biol. 2008;10(7):825-836.

17. Childs BG, et al. Senescent cells: an emerging target for diseases of ageing. Nat Rev Drug Discov. 2017;16(10):718-735.

18. Hayflick L, Moorhead PS. The serial cultivation of human diploid cell strains. Exp Cell Res. 1961;25:585-621.

19. Hayflick L. The limited in vitro lifetime of human diploid cell strains. Exp Cell Res. 1965;37:614-636

20. Harley CB, Vaziri H, Counter CM, Allsopp RC. The telomere hypothesis of cellular aging. Exp Gerontol. 1992;27(4):375-382.

21. Allsopp RC, et al. Telomere length predicts replicative capacity of human fibroblasts. Proc Natl Acad Sci U S A. 1992;89(21):10114-10118.

22. Lu W, Zhang Y, Liu D, Songyang Z, Wan M. Telomeres - structure, function, and regulation. Exp Cell Res. 2013;319(2):133-141.

23. O’Sullivan RJ, Karlseder J. Telomeres: protecting chromosomes against genome instability. Nat Rev Mol Cell Biol. 2010;11(3):171-181.

24. Di Micco R, et al. Oncogene-induced senescence is a DNA damage response triggered by DNA hyper-replication. Nature. 2006;444(7119):638-642.

25. Mallette FA, Gaumont-Leclerc MF, Ferbeyre G. The DNA damage signaling pathway is a critical mediator of oncogene-induced senescence. Genes Dev. 2007;21(1):43-48.

26. Webley K, et al. Posttranslational modifications of 553 in replicative senescence overlapping but distinct from those induced by DNA damage. $\mathrm{Mol}$ Cell Biol. 2000;20(8):2803-2808.

27. Alcorta DA, Xiong Y, Phelps D, Hannon G, Beach D, Barrett JC. Involvement of the cyclin-dependent kinase inhibitor p16 (INK4a) in replicative senescence of normal human fibroblasts. Proc Natl Acad Sci U S A. 1996;93(24):13742-13747.

28. Narita M, et al. Rb-mediated heterochromatin formation and silencing of E2F target genes during cellular senescence. Cell. 2003;113(6):703-716.

29. David G. Regulation of oncogene-induced cell cycle exit and senescence by chromatin modifiers. Cancer Biol Ther. 2012;13(11):992-1000.
30. Hoare M, et al. NOTCH1 mediates a switch between two distinct secretomes during senescence. Nat Cell Biol. 2016;18(9):979-992.

31. Kuilman T, Peeper DS. Senescence-messaging secretome: SMS-ing cellular stress. Nat Rev Cancer. 2009;9(2):81-94.

32. Jin B, Wang Y, Wu CL, Liu KY, Chen H, Mao ZB. PIM-1 modulates cellular senescence and links IL-6 signaling to heterochromatin formation. Aging Cell. 2014;13(5):879-889.

33. Kuilman T, et al. Oncogene-induced senescence relayed by an interleukin-dependent inflammatory network. Cell. 2008;133(6):1019-1031.

34. Rodier F, et al. DNA-SCARS: distinct nuclear structures that sustain damage-induced senescence growth arrest and inflammatory cytokine secretion. JCell Sci. 2011;124(pt 1):68-81.

35. Freund A, Patil CK, Campisi J.p38MAPK is a novel DNA damage response-independent regulator of the senescence-associated secretory phenotype. EMBO J. 2011;30(8):1536-1548.

36. Laberge RM, et al. MTOR regulates the protumorigenic senescence-associated secretory phenotype by promoting IL1A translation. Nat Cell Biol. 2015;17(8):1049-1061.

37. Demaria M, et al. An essential role for senescent cells in optimal wound healing through secretion of PDGF-AA. Dev Cell. 2014;31(6):722-733.

38. Baker DJ, et al. Clearance of p16Ink4a-positive senescent cells delays ageing-associated disorders. Nature. 2011;479(7372):232-236.

39. Weber MA, Neutel JM, Cheung DG. Hypertension in the aged: a pathophysiologic basis for treatment. Am J Cardiol. 1989;63(16):25H-32H.

40. Safar ME. Systolic hypertension in the elderly: arterial wall mechanical properties and the renin-angiotensin-aldosterone system. J Hypertens. 2005;23(4):673-681.

41. Strait JB, Lakatta EG. Aging-associated cardiovascular changes and their relationship to heart failure. Heart Fail Clin. 2012;8(1):143-164.

42. Franklin SS, Jacobs MJ, Wong ND, L'Italien GJ, Lapuerta P. Predominance of isolated systolic hypertension among middle-aged and elderly US hypertensives: analysis based on National Health and Nutrition Examination Survey (NHANES) III. Hypertension. 2001;37(3):869-874.

43. Lam CS, et al. Aortic root remodeling over the adult life course: longitudinal data from the Framingham Heart Study. Circulation. 2010;122(9):884-890.

44. Dai X, Hummel SL, Salazar JB, Taffet GE, Zieman 
S, Schwartz JB. Cardiovascular physiology in the older adults. J Geriatr Cardiol. 2015;12(3):196-201.

45. Cattell MA, Hasleton PS, Anderson JC. Increased elastin content and decreased elastin concentration may be predisposing factors in dissecting aneurysms of human thoracic aorta. Cardiovasc Res. 1993;27(2):176-181.

46. Sariola H, Viljanen T, Luosto R. Histological pattern and changes in extracellular matrix in aortic dissections. JClin Pathol.1986;39(10):1074-1081.

47. Tsamis A, Krawiec JT, Vorp DA. Elastin and collagen fibre microstructure of the human aorta in ageing and disease: a review. JR Soc Interface. 2013;10(83):20121004.

48. Lakatta EG. Arterial and cardiac aging: major shareholders in cardiovascular disease enterprises. Part III: cellular and molecular clues to heart and arterial aging. Circulation. 2003;107(3):490-497.

49. Napoli C, et al. Effects of nitric oxide on cell proliferation: novel insights. J Am Coll Cardiol. 2013;62(2):89-95.

50. Yoshimura M, et al. Genetic risk factors for coronary artery spasm: significance of endothelial nitric oxide synthase gene T-786-->C and missense Glu298Asp variants. J Investig Med. 2000;48(5):367-374.

51. Kinlay S. Coronary artery spasm as a cause of angina. Circulation. 2014;129(17):1717-1719.

52. Liao JK. Linking endothelial dysfunction with endothelial cell activation. JClin Invest. 2013;123(2):540-541.

53. Montezano AC, Touyz RM. Reactive oxygen species and endothelial function - role of nitric oxide synthase uncoupling and Nox family nicotinamide adenine dinucleotide phosphate oxidases. Basic Clin Pharmacol Toxicol. 2012;110(1):87-94.

54. Lee HY, Zeeshan HMA, Kim HR, Chae HJ. Nox4 regulates the eNOS uncoupling process in aging endothelial cells. Free Radic Biol Med. 2017;113:26-35.

55. Yang YM, Huang A, Kaley G, Sun D. eNOS uncoupling and endothelial dysfunction in aged vessels. Am J Physiol Heart Circ Physiol. 2009;297(5):H1829-H1836.

56. Yucel C, et al. Left ventricular hypertrophy and arterial stiffness in essential hypertension. Bratisl Lek Listy. 2015;116(12):714-718.

57. Carrick-Ranson G, et al. Effect of healthy aging on left ventricular relaxation and diastolic suction. Am J Physiol Heart Circ Physiol. 2012;303(3):H315-H322.

58. Pellett AA, Myers L, Welsch M, Jazwinski SM, Welsh DA. Left atrial enlargement and reduced physical function during aging. J Aging Phys Act. 2013;21(4):417-432.

59. Gerstenblith G, Frederiksen J, Yin FC, Fortuin NJ, Lakatta EG, Weisfeldt ML. Echocardiographic assessment of a normal adult aging population. Circulation. 1977;56(2):273-278.

60. Jiao Q, Takeshima H, Ishikawa Y, Minamisawa S. Sarcalumenin plays a critical role in agerelated cardiac dysfunction due to decreases in SERCA2a expression and activity. Cell Calcium. 2012;51(1):31-39.

61. Fernandez-Sanz C, et al. Defective sarcoplasmic reticulum-mitochondria calcium exchange in aged mouse myocardium. Cell Death Dis. 2014;5:e1573.

62. Janczewski AM, Lakatta EG. Modulation of sarcoplasmic reticulum $\mathrm{Ca}(2+)$ cycling in systolic and diastolic heart failure associated with aging. Heart Fail Rev. 2010;15(5):431-445.

63. Menke J, Lüthje L, Kastrup A, Larsen J. Thromboembolism in atrial fibrillation. Am J Cardiol. 2010;105(4):502-510.

64. Struthers AD. Pathophysiology of heart failure following myocardial infarction. Heart. 2005;91(supp 2):ii14-ii16; discussion ii31, ii43-ii48.

65. Davies PF. Hemodynamic shear stress and the endothelium in cardiovascular pathophysiology. Nat Clin Pract Cardiovasc Med. 2009;6(1):16-26.

66. John M. Eisenberg Center for Clinical Decisions and Communications Science. Treatments for open-angle glaucoma: a review of the research for adults. In: Comparative Effectiveness Review Summary Guides for Consumers [Internet]. Rockville, Maryland, USA: Agency for Healthcare Research and Quality; 2005. https://www.ncbi. nlm.nih.gov/books/NBK131775/. Accessed January 29, 2018.

67. Boon RA, et al. MicroRNA-34a regulates cardiac ageing and function. Nature. 2013;495(7439):107-110.

68. Torella D, et al. Cardiac stem cell and myocyte aging, heart failure, and insulin-like growth factoroverexpression. Circ Res. 2004;94(4):514-524.

69. Terai M, et al. Association of telomere shortening in myocardium with heart weight gain and cause of death. Sci Rep. 2013;3:2401.

70. Hewitt G, et al. Telomeres are favoured targets of a persistent DNA damage response in ageing and stress-induced senescence. Nat Commun. 2012;3:708

71. Fumagalli M, et al. Telomeric DNA damage is irreparable and causes persistent DNA-damageresponse activation. Nat Cell Biol. 2012;14(4):355-365.

72. Miyawaki A, et al. Adult murine cardiomyocytes exhibit regenerative activity with cell cycle reentry through STAT3 in the healing process of myocarditis. Sci Rep. 2017;7(1):1407.

73. Almaida-Pagán PF, Lucas-Sánchez A, Tocher DR. Changes in mitochondrial membrane composition and oxidative status during rapid growth, maturation and aging in zebrafish, Danio rerio. Biochim Biophys Acta. 2014;1841(7):1003-1011.

74. Tatarková Z, et al. Effects of aging on activities of mitochondrial electron transport chain complexes and oxidative damage in rat heart. Physiol Res. 2011;60(2):281-289.

75. Lesnefsky EJ, et al. Aging decreases electron transport complex III activity in heart interfibrillar mitochondria by alteration of the cytochrome $\mathrm{c}$ binding site. J Mol Cell Cardiol. 2001;33(1):37-47.

76. Lee HY, et al. Targeted expression of catalase to mitochondria prevents age-associated reductions in mitochondrial function and insulin resistance. Cell Metab. 2010;12(6):668-674.

77. Dai DF, et al. Mitochondrial-targeted catalase: extended longevity and the roles in various disease models. Prog Mol Biol Transl Sci. 2017;146:203-241.

78. Cesselli D, et al. Effects of age and heart failure on human cardiac stem cell function. Am J Pathol. 2011;179(1):349-366.
79. Kajstura J, et al. Myocyte turnover in the aging human heart. Circ Res. 2010;107(11):1374-1386.

80. Morgan RG, et al. Age-related telomere uncapping is associated with cellular senescence and inflammation independent of telomere shortening in human arteries. Am J Physiol Heart Circ Physiol. 2013;305(2):H251-H258.

81. Kushner EJ, Van Guilder GP, Maceneaney OJ, Cech JN, Stauffer BL, DeSouza CA. Aging and endothelial progenitor cell telomere length in healthy men. Clin Chem Lab Med. 2009;47(1):47-50.

82. Kushner EJ, MacEneaney OJ, Weil BR, Greiner JJ, Stauffer BL, DeSouza CA. Aging is associated with a proapoptotic endothelial progenitor cell phenotype. J Vasc Res. 2011;48(5):408-414.

83. Donato AJ, et al. Direct evidence of endothelial oxidative stress with aging in humans: relation to impaired endothelium-dependent dilation and upregulation of nuclear factor-kappaB. Circ Res. 2007;100(11):1659-1666

84. Durrant JR, et al. Voluntary wheel running restores endothelial function in conduit arteries of old mice: direct evidence for reduced oxidative stress, increased superoxide dismutase activity and down-regulation of NADPH oxidase. JPhysiol (Lond). 2009;587(pt 13):3271-3285.

85. Miller SJ, et al. Development of progressive aortic vasculopathy in a rat model of aging. Am J Physiol Heart Circ Physiol. 2007;293(5):H2634-H2643.

86. Imanishi T, Hano T, Nishio I. Angiotensin II accelerates endothelial progenitor cell senescence through induction of oxidative stress. JHypertens. 2005;23(1):97-104.

87. Endtmann C, et al. Angiotensin II impairs endothelial progenitor cell number and function in vitro and in vivo: implications for vascular regeneration. Hypertension. 2011;58(3):394-403.

88. Pierce GL, Lesniewski LA, Lawson BR, Beske $\mathrm{SD}$, Seals DR. Nuclear factor-kB activation contributes to vascular endothelial dysfunction via oxidative stress in overweight/obese middle-aged and older humans. Circulation. 2009;119(9):1284-1292.

89. van der Loo B, et al. Enhanced peroxynitrite formation is associated with vascular aging. J Exp Med. 2000;192(12):1731-1744.

90. Dimri GP, et al. A biomarker that identifies senescent human cells in culture and in aging skin in vivo. Proc Natl Acad Sci U S A. 1995;92(20):9363-9367.

91. Krishnamurthy J, et al. Ink4a/Arf expression is a biomarker of aging. J Clin Invest. 2004;114(9):1299-1307.

92. Cudejko C, et al. p16INK4a deficiency promotes IL-4-induced polarization and inhibits proinflammatory signaling in macrophages. Blood. 2011;118(9):2556-2566.

93. Rota M, et al. The young mouse heart is composed of myocytes heterogeneous in age and function. Circ Res. 2007;101(4):387-399.

94. Niizuma S, et al. Effect of persistent activation of phosphoinositide 3-kinase on heart. Life Sci. 2012;90(15-16):619-628.

95. Maejima Y, Adachi S, Ito H, Hirao K, Isobe M. Induction of premature senescence in cardiomyocytes by doxorubicin as a novel mechanism of myocardial damage. Aging Cell. 2008;7(2):125-136. 96. Soonpaa MH, Field LJ. Assessment of cardio- 
myocyte DNA synthesis in normal and injured adult mouse hearts. Am J Physiol. 1997;272(1 pt 2): $\mathrm{H} 22 \mathrm{O}-\mathrm{H} 226$

97. Bergmann O, et al. Evidence for cardiomyocyte renewal in humans. Science. 2009;324(5923):98-102.

98. Walsh S, Ponten A, Fleischmann BK, Jovinge S. Cardiomyocyte cell cycle control and growth estimation in vivo - an analysis based on cardiomyocyte nuclei. Cardiovasc Res. 2010;86(3):365-373.

99. Beltrami AP, et al. Adult cardiac stem cells are multipotent and support myocardial regeneration. Cell. 2003;114(6):763-776.

100.Orlic D, et al. Bone marrow cells regenerate infarcted myocardium. Nature. 2001;410(6829):701-705.

101. Kikuchi K, et al. Primary contribution to zebrafish heart regeneration by gata $4(+)$ cardiomyocytes. Nature. 2010;464(7288):601-605.

102. Senyo SE, et al. Mammalian heart renewal by pre-existing cardiomyocytes. Nature. 2013;493(7432):433-436.

103. Rossman MJ, et al. Endothelial cell senescence with aging in healthy humans: prevention by habitual exercise and relation to vascular endothelial function. Am J Physiol Heart Circ Physiol. 2017;313(5):H890-H895.

104. Olmos G, et al. Hyperphosphatemia induces senescence in human endothelial cells by increasing endothelin-1 production. Aging Cell. 2017;16(6):1300-1312.

105. Yang D, et al. Increased polyploidy in aortic vascular smooth muscle cells during aging is marked by cellular senescence. Aging Cell. 2007;6(2):257-260.

106.McCrann DJ, Yang D, Chen H, Carroll S, Ravid K. Upregulation of Nox 4 in the aging vasculature and its association with smooth muscle cell polyploidy. Cell Cycle. 2009;8(6):902-908.

107. Ragnauth CD, et al. Prelamin A acts to accelerate smooth muscle cell senescence and is a novel biomarker of human vascular aging. Circulation 2010;121(20):2200-2210.

108. de Cavanagh EM, Inserra F, Ferder L. Angiotensin II blockade: a strategy to slow ageing by protecting mitochondria? Cardiovasc Res. 2011;89(1):31-40.

109. Hayashi T, Yano K, Matsui-Hirai H, Yokoo H, Hattori Y, Iguchi A. Nitric oxide and endothelial cellular senescence. Pharmacol Ther. 2008;120(3):333-339.

110. Hayashi T, et al. Endothelial cellular senescence is inhibited by nitric oxide: implications in atherosclerosis associated with menopause and diabetes. Proc Natl Acad Sci U S A. 2006;103(45):17018-17023.

111. Vasa M, Breitschopf K, Zeiher AM, Dimmeler S. Nitric oxide activates telomerase and delays endothelial cell senescence. Circ Res. 2000;87(7):540-542.

112. Zhu C, Yu Y, Montani JP, Ming XF, Yang Z. Arginase-I enhances vascular endothelial inflammation and senescence through eNOS-uncoupling. BMC Res Notes. 2017;10(1):82.

113. Serrano M, Lin AW, McCurrach ME, Beach D, Lowe SW. Oncogenic ras provokes premature cell senescence associated with accumulation of $\mathrm{p} 53$ and p16INK4a. Cell. 1997;88(5):593-602.

114. Kunieda T, et al. Angiotensin II induces premature senescence of vascular smooth muscle cells and accelerates the development of atherosclerosis via a p21-dependent pathway. Circulation. 2006;114(9):953-960.

115. Minamino T, et al. Ras induces vascular smooth muscle cell senescence and inflammation in human atherosclerosis. Circulation. 2003;108(18):2264-2269.

116. Wang M, et al. Aging increases aortic MMP-2 activity and angiotensin II in nonhuman primates. Hypertension. 2003;41(6):1308-1316.

117. Matsumoto T, Baker DJ, d'Uscio LV, Mozammel G, Katusic ZS, van Deursen JM. Aging-associated vascular phenotype in mutant mice with low levels of BubR1. Stroke. 2007;38(3):1050-1056.

118. Weber C, Noels H. Atherosclerosis: current pathogenesis and therapeutic options. Nat Med. 2011;17(11):1410-1422.

119. Tabas I, García-Cardeña G, Owens GK. Recent insights into the cellular biology of atherosclerosis. J Cell Biol. 2015;209(1):13-22.

120. Palombo C, Kozakova M. Arterial stiffness, atherosclerosis and cardiovascular risk: pathophysiologic mechanisms and emerging clinical indications. Vascul Pharmacol. 2016;77:1-7.

121. Zhang J, Patel JM, Block ER. Enhanced apoptosis in prolonged cultures of senescent porcine pulmonary artery endothelial cells. Mech Ageing Dev. 2002;123(6):613-625.

122. Krouwer VJ, Hekking LH, Langelaar-Makkinje M, Regan-Klapisz E, Post JA. Endothelial cell senescence is associated with disrupted cell-cell junctions and increased monolayer permeability. Vasc Cell. 2012;4(1):12.

123. Spinetti G, Wang M, Monticone R, Zhang J, Zhao D, Lakatta EG. Rat aortic MCP-1 and its receptor CCR2 increase with age and alter vascular smooth muscle cell function. Arterioscler Thromb Vasc Biol. 2004;24(8):1397-1402.

124. Song Y, Shen H, Schenten D, Shan P, Lee PJ, Goldstein DR. Aging enhances the basal production of IL- 6 and CCL2 in vascular smooth muscle cells. Arterioscler Thromb Vasc Biol. 2012;32(1):103-109.

125. Minamino T, Miyauchi H, Yoshida T, Komuro I. [Endothelial cell senescence in human atherosclerosis: role of telomeres in endothelial dysfunction] (article in Japanese). JCardiol. 2003;41(1):39-40.

126. Finn AV, Nakano M, Narula J, Kolodgie FD, Virmani R. Concept of vulnerable/unstable plaque. Arterioscler Thromb Vasc Biol. 2010;30(7):1282-1292.

127. Khanna AK. Enhanced susceptibility of cyclin kinase inhibitor p21 knockout mice to high fat diet induced atherosclerosis. J Biomed Sci. 2009;16:66.

128. Díez-Juan A, Andrés V. The growth suppressor p27(Kip1) protects against diet-induced atherosclerosis. FASEB J. 2001;15(11):1989-1995.

129. Mercer J, Figg N, Stoneman V, Braganza D, Bennett MR. Endogenous $\mathrm{p} 53$ protects vascular smooth muscle cells from apoptosis and reduces atherosclerosis in ApoE knockout mice. Circ Res. 2005;96(6):667-674.

130. Helgadottir A, et al. A common variant on chromosome 9p21 affects the risk of myocardial infarction. Science. 2007;316(5830):1491-1493.

131. McPherson R, et al. A common allele on chromosome 9 associated with coronary heart disease. Science. 2007;316(5830):1488-1491.

132. Yap KL, et al. Molecular interplay of the noncoding RNA ANRIL and methylated histone $\mathrm{H} 3$ lysine 27 by polycomb $\mathrm{CBX} 7$ in transcriptional silencing of INK4a. Mol Cell. 2010;38(5):662-674.

133. Kotake $\mathrm{Y}$, et al. Long non-coding RNA ANRIL is required for the PRC2 recruitment to and silencing of p15(INK4B) tumor suppressor gene. Oncogene. 2011;30(16):1956-1962.

134. Jarinova $\mathrm{O}$, et al. Functional analysis of the chromosome 9 p21.3 coronary artery disease risk locus. Arterioscler Thromb Vasc Biol. 2009;29(10):1671-1677.

135. Visel A, et al. Targeted deletion of the $9 \mathrm{p} 21$ non-coding coronary artery disease risk interval in mice. Nature. 2010;464(7287):409-412.

136. Almontashiri NA, et al. 9p21.3 Coronary artery disease risk variants disrupt TEAD transcription factor-dependent transforming growth factor $\beta$ regulation of $\mathrm{p} 16$ expression in human aortic smooth muscle cells. Circulation. 2015;132(21):1969-1978.

137. Lugo R, et al. Heterotypic paracrine signaling drives fibroblast senescence and tumor progression of large cell carcinoma of the lung. Oncotarget. 2016;7(50):82324-82337.

138. Akasheva DU, et al. Age-related left ventricular changes and their association with leukocyte telomere length in healthy people. PLoS One. 2015;10(8): 0135883.

139. Olivetti G, Melissari M, Capasso JM, Anversa P. Cardiomyopathy of the aging human heart. Circ Res. 1991;68(6):1560-1568.

140. Christou DD, Seals DR. Decreased maximal heart rate with aging is related to reduced $\beta$ adrenergic responsiveness but is largely explained by a reduction in intrinsic heart rate. J Appl Physiol. 2008;105(1):24-29.

141. Buja LM, Vela D. Cardiomyocyte death and renewal in the normal and diseased heart. Cardiovasc Pathol. 2008;17(6):349-374.

142. Chimenti $C$, et al. Senescence and death of primitive cells and myocytes lead to premature cardiac aging and heart failure. Circ Res. 2003;93(7):604-613.

143. Leri A, et al. Ablation of telomerase and telomere loss leads to cardiac dilatation and heart failure associated with p53 upregulation. $E M B O J$. 2003;22(1):131-139.

144.Gevaert AB, et al. Endothelial senescence contributes to heart failure with preserved ejection fraction in an aging mouse model. Circ Heart Fail. 2017;10(6): e003806.

145.Zucker IH, Xiao L, Haack KK. The central renin-angiotensin system and sympathetic nerve activity in chronic heart failure. Clin Sci. 2014;126(10):695-706.

146.Regan JA, et al. A mouse model of heart failure with preserved ejection fraction due to chronic infusion of a low subpressor dose of angiotensin II. Am J Physiol Heart Circ Physiol. 2015;309(5):H771-H778.

147. Fukuta H, Goto T, Wakami K, Ohte N. Effect of renin-angiotensin system inhibitors on mortality in heart failure with preserved ejection fraction: 
a meta-analysis of observational cohort and randomized controlled studies. Heart Fail Rev. 2017;22(6):775-782.

148.Silva AR, Martini A, Neves FA. Aliskiren, enalapril, or both in heart failure. $N$ Engl JMed. 2016;375(7):701-702.

149. Pacurari M, Kafoury R, Tchounwou PB, Ndebele $\mathrm{K}$. The renin-angiotensin-aldosterone system in vascular inflammation and remodeling. Int J Inflam. 2014;2014:689360.

150. Morita N, Mandel WJ, Kobayashi Y, Karagueuzian HS. Cardiac fibrosis as a determinant of ventricular tachyarrhythmias. J Arrhythm. 2014;30(6):389-394.

151. Jun JI, Lau LF. The matricellular protein CCN1 induces fibroblast senescence and restricts fibrosis in cutaneous wound healing. Nat Cell Biol. 2010;12(7):676-685.

152. Krizhanovsky V, et al. Senescence of activated stellate cells limits liver fibrosis. Cell. 2008;134(4):657-667.

153. Meyer K, Hodwin B, Ramanujam D, Engelhardt $\mathrm{S}$, Sarikas A. Essential role for premature senescence of myofibroblasts in myocardial fibrosis. J Am Coll Cardiol. 2016;67(17):2018-2028.

154. Xie J, et al. Premature senescence of cardiac fibroblasts and atrial fibrosis in patients with atrial fibrillation. Oncotarget. 2017;8(35):57981-57990.

155. Zhu F, et al. Senescent cardiac fibroblast is critica for cardiac fibrosis after myocardial infarction. PLoS One. 2013;8(9):e74535.

156. Muñoz-Espín D, et al. Programmed cell senescence during mammalian embryonic development. Cell. 2013;155(5):1104-1118.

157. Storer M, et al. Senescence is a developmental mechanism that contributes to embryonic growth and patterning. Cell. 2013;155(5):1119-1130.

158. Chuprin A, et al. Cell fusion induced by ERVWE1 or measles virus causes cellular senescence. Genes Dev. 2013;27(21):2356-2366.

159. Game FL, et al. Effectiveness of interventions to enhance healing of chronic ulcers of the foot in diabetes: a systematic review. Suppl. 2016;1:154-168.

160.Tombor B, Rundell K, Oltvai ZN. Bcl-2 promotes premature senescence induced by oncogenic Ras. Biochem Biophys Res Commun. 2003;303(3):800-807.

161. Rincheval V, et al. Bcl-2 can promote p53dependent senescence versus apoptosis without affecting the G1/S transition. Biochem Biophys Res Commun. 2002;298(2):282-288.

162.Yosef R, et al. Directed elimination of senescent cells by inhibition of BCL-W and BCL-XL. Nat Commun. 2016;7:11190.

163. Kruiswijk F, Labuschagne CF, Vousden KH. p53 in survival, death and metabolic health: a lifeguard with a licence to kill. Nat Rev Mol Cell Biol. 2015;16(7):393-405.

164. Chang J, et al. Clearance of senescent cells by ABT263 rejuvenates aged hematopoietic stem cells in mice. Nat Med. 2016;22(1):78-83.

165. Baar MP, et al. Targeted apoptosis of senescent cells restores tissue homeostasis in response to chemotoxicity and aging. Cell. 2017;169(1):132-147.e16.

166. Samaraweera L, Adomako A, Rodriguez-Gabin A, McDaid HM. A novel indication for Panobinostat as a senolytic drug in NSCLC and HNSCC. Sci Rep. 2017;7(1):1900.

167. Fuhrmann-Stroissnigg $\mathrm{H}$, et al. Identification of HSP9O inhibitors as a novel class of senolytics.
Nat Commun. 2017;8(1):422.

168. Wang Y, et al. Discovery of piperlongumine as a potential novel lead for the development of senolytic agents. Aging (Albany NY). 2016;8(11):2915-2926.

169.Zhu Y, et al. The Achilles' heel of senescent cells: from transcriptome to senolytic drugs. Aging Cell. 2015;14(4):644-658.

170. Roos CM, et al. Chronic senolytic treatment alleviates established vasomotor dysfunction in aged or atherosclerotic mice. Aging Cell. 2016;15(5):973-977.

171. Jeon $\mathrm{OH}$, et al. Local clearance of senescent cells attenuates the development of post-traumatic osteoarthritis and creates a pro-regenerative environment. Nat Med. 2017;23(6):775-781.

172. Simard T, Hibbert B, Ramirez FD, Froeschl M, Chen YX, O'Brien ER. The evolution of coronary stents: a brief review. Can J Cardiol. 2014;30(1):35-45.

173. Sharpless NE, Sherr CJ. Forging a signature of in vivo senescence. Nat Rev Cancer. 2015;15(7):397-408.

174. Hall BM, et al. Aging of mice is associated with p16(Ink4a)- and $\beta$-galactosidase-positive macrophage accumulation that can be induced in young mice by senescent cells. Aging (Albany NY). 2016;8(7):1294-1315.

175. Hall BM, et al. p16(Ink4a) and senescenceassociated $\beta$-galactosidase can be induced in macrophages as part of a reversible response to physiological stimuli. Aging (Albany NY). 2017;9(8):1867-1884

176. Prattichizzo F, Bonafè M, Olivieri F, Franceschi C. Senescence associated macrophages and "macroph-aging": are they pieces of the same puzzle? Aging (Albany NY). 2016;8(12):3159-3160. 